University of Warwick institutional repository: http://go.warwick.ac.uk/wrap This paper is made available online in accordance with publisher policies. Please scroll down to view the document itself. Please refer to the repository record for this item and our policy information available from the repository home page for further information.

To see the final version of this paper please visit the publisher's website. Access to the published version may require a subscription.

Author(s): Edward A. Page

Article Title: Fairness on the Day after Tomorrow: Justice, Reciprocity and Global Climate Change

Year of publication: 2007 Link to published version: http://dx.doi.org/10.1111/j.1467-9248.2007.00649.x Publisher statement: The definitive version is available at www.blackwell-synergy.com 


\section{Fairness on the Day After Tomorrow: Justice, Reciprocity and Global Climate Change}

Climate change raises important questions of global distributive justice, which can be defined as the issue of how benefits and burdens should be distributed within and between generations. This article addresses two conceptual issues that underpin the relationship between climate change and the part of distributive justice concerned with the entitlements of future persons. The first is the role of reciprocity, conceived either as mutual advantage or fair play, in the allocation of distributive entitlements between generations. The second is the extent to which theories of 'justice as reciprocity' can ground duties of intergenerational justice that underpin radical policies to manage the causes and impacts of global climate change. I argue that theories of justice as fair reciprocity generate significant duties of environmental conservation, despite these duties not being owed directly to the not-yet-born.

Global climate change, understood as an ongoing and complex pattern of changes in the composition of the earth's atmosphere arising from human activity or natural variability, has attracted enormous interest amongst natural and socialscientists in recent years. While it has been long understood that numerous natural transformations of the Earth's atmosphere have occurred over its history, a strong consensus has only recently emerged that human behaviour can affect the atmosphere in ways that will have significant impacts on future generations. ${ }^{1} \mathrm{~A}$ 
number of impact analyses have indicated that the climate changes involved will be generally, if not uniformly, adverse for future populations (McMichael and Githeko, 2001; Tol, 2002; Schellnhuber et al, 2006, pp. 133-202). Climate change is, in addition, consistently reported as one of the most pressing problems facing the world in surveys of elite and public opinion, even if there remains considerable disagreement as to the appropriate response to the problem (Page, 2006, pp. 7ff).

While climate change raises a number of important issues for political scientists and theorists, a key set of questions concerns the interface between climate change and the emerging field of global distributive justice, understood as the issue of how benefits and burdens should be distributed within and between generations. A host of intergovernmental reports and philosophical analyses have argued that climate policies must be consistent with international and intergenerational justice in order for them to secure the legitimacy needed to be effective in meeting their aims and objectives. ${ }^{2}$ In particular, there has arisen a broad consensus around the objective, first outlined in the United Nations Framework Convention on Climate Change (UNFCCC), that a global solution to climate change must as a matter of justice prevent 'dangerous anthropogenic interference with the climate system' (United Nations, 1995, p. 5; Adger et al, 2006, Paavola and Adger, 2006).

While there have been a number of attempts in recent years to construct theories of justice that explain our environmental duties to future generations, there have been few systematic evaluations of the objectives laid out in the UNFCCC, or the normative assumptions that lie behind these objectives. In this article, I will be 
investigating one set of reasons for thinking that the philosophical basis of our obligations to members of future generations, for example to tackle the origins and impacts of climate change, is more complex than is often assumed. The discussion will focus on the challenge to intergenerational justice that arises from giving foundational value to the notion of reciprocity, considered either as mutual advantage or fair play.

Duties of reciprocity have tended to be overlooked in the literature on intergenerational justice in favour of more fashionable theories of distribution such as contractualism (Kumar, 2003, pp. 105ff), communitarianism (De Shalit, 1995, pp. 13ff), and impersonal consequentialism (Broome, 1992, pp. 27ff). Yet, there is a significant ethic of reciprocity running through many historical and contemporary discussions of our duties to posterity which has not been fully explored and which, more importantly, seems immune to some of the difficulties that plague rival approaches. Theories of justice as reciprocity are not obviously prone to the problem of extending contractual methodologies to explore the claims of individuals whose existence will be contingent on the rules being explored by the contract device; they do not reduce intergenerational justice to a matter only of preserving the values of one's community; and they do not imply perpetual pressure to increase the population in order to maximise total welfare.

In what follows, I provide an overview of two influential 'reciprocity-based' accounts of distributive justice. I then show that neither account, without modification, can be extended beyond the context of the present generation. I then go on to explore how reciprocity-based theories that invoke the idea of reciprocity as fair play, rather than mutual advantage, can be modified so that they generate 
significant duties of intergenerational conservation, despite these duties not being owed directly to the not-yet-born. I argue that such modifications provide a useful addition to the range of ethical approaches that converge on a global and tough approach to the origins and effects of climate change.

\section{RECIPROCITY-BASED JUSTICE}

The key feature of theories of distributive justice as reciprocity is the assumption that only individuals who contribute to the well-being of others are entitled to a full and fair share of society's resources. ${ }^{3}$ We might call this the 'contribution requirement.' The contribution requirement can be used to specify both the 'scope' and the 'content' of distributive justice. That is, it can be used to determine which entities possess entitlements to social benefits; which entities are bound by duties to provide these benefits; and the size of the share that each person is entitled to in terms of some currency of justice. The essence of the contribution requirement is that a person's non-strategic capabilities, such as their needs or interests, do not in themselves generate valid claims to social resources.

While there are many ways in which the contribution requirement might operate within a theory of distributive justice, two main theories of justice as reciprocity have emerged in the literature. The first proposes that requirements of justice are determined by considerations of self-interest; the second proposes that these requirements are determined by considerations of fairness (or fair play)

According to 'Justice as Self-Interested Reciprocity', requirements of justice must be consistent with the pursuit of advantage of the individuals who are bound by 
them. The idea is that entitlements to social benefits are distributed in strict proportion to people's contributions or their bargaining position relative to others (these two formulations can diverge, but I put this possibility aside). One example of justice as self-interested reciprocity is found in the writings of David Gauthier. In Morals by Agreement, Gauthier argued that norms of distributive justice are generated as 'a rational constraint from the non-moral premises of rational choice' (Gauthier, 1986, p. 4). The idea is that norms of justice are defensible only insofar as they can be shown to be rational, and they are rational only if they are in the interests of the individuals they bind, where the prime motivation of all individuals is assumed to be the pursuit of their own advantage. As 'constrained utility maximisers', Gauthier argued, rational individuals will cooperate with others who are similarly disposed by respecting certain norms of justice so long as (1) it is in their own interest and (2) the selection of these norms is the outcome of a bargaining situation that reflects the differential resources of the participants. So long as these two conditions are satisfied, the logic of self-interested reciprocity can be relied upon generate constraints on human behaviour 'as the minimum price that has to be paid in order to obtain the co-operation of others' (Barry, 1989, p. 6).

According to the second way of linking justice and reciprocity, 'Justice as Fair Reciprocity', it is a particular notion of fairness, and not merely prudence, which lies at the heart of our obligations to others. Adopting the idea that behaving unfairly is unjust regardless of its prudential value enables proponents of this approach to sidestep the powerful criticism of self-interested reciprocity that it has no way of explaining why schemes of social cooperation that exclude the 
impoverished from social benefits are unjust (Barry, 1995, pp. 33ff). Gauthier, for example, makes it clear that only those who are already capable of fruitful cooperation, and who belong to an already existing framework, can be recognised as possessing claims of justice (Gauthier, 1986, pp. 283-7). Justice as fair reciprocity, by contrast, since it allocates intrinsic moral value to dealings of fair play, will outlaw extreme forms of exclusion on the grounds that they are an affront to the notion of fairness (Smith, 2003, p. 245; White, 2003, pp. 49ff).

The essence of justice as fair reciprocity was captured by John Rawls, who claimed that members of just societies 'are not to gain from the co-operative labours of others without doing [their] fair share' (Rawls, 1971, p. 112). Similarly, Stuart White argues that 'if one willingly enjoys the fruits of one's fellow citizens' labours, then, as a matter of justice, one ought to provide some appropriate good or service in return' (White, 2003, p. 49). Yet, a serious complication with such declarations of fair reciprocity is that notions of 'doing our fair share' and of 'providing some appropriate good for others' are wide open to interpretation (Arneson, 1997, pp. 339ff; Smith, 2001, pp. 32ff; Becker, 2005). As Becker notes, subtly different conceptions of fair reciprocity operate in a wide range of social contexts, each attempting 'to turn the general concept [of fair reciprocity] into a more determinate set of norms and standards’ (Becker, 2005, p.18)

According to one popular conception of fair reciprocity, 'doing one’s fair share' involves the exchange of benefits of equal size. We might call this 'benefit reciprocity.' Benefit reciprocity is an important category of fair-reciprocity, but not exhaustive of it. Some theorists have proposed that equivalent sacrifices, in 
contrast to equivalent benefits, are the key to fair reciprocity. The idea is that the costs of performing some reciprocal duties are much higher for some than the costs of performing the actions that ground these duties, so it would be unfair to require equivalent exchanges in these cases (White, 2003, pp. 66ff; Becker, 2005, p.27). Suppose that developing countries had contributed as much to the origins of climate change as developed countries. It would still not seem fair to expect these countries to bear the same absolute burden to mitigate or adapt to the problem as richer countries since they have far less capacity. Rather, it would be appropriate only to require a contribution from the developed world, considered either in collective or non-collective terms, that reflects its capacity. Yet, a contribution would still have to be made, on this view, since fair reciprocity obtains only when all parties contribute something to the costs of a collaborative activity. The notion of 'cost reciprocity', as we might call it, is an integral element of the UNFCCC, which states that 'The Parties should protect the climate system for the benefit of present and future generations of humankind, on the basis of equality and in accordance with their respective responsibilities and respective capabilities' (United Nations, 1995, p. 5).

Both benefit and cost reciprocity are most usefully applied in the context of faceto-face transactions between individuals that are uncoerced. However, they are more difficult to apply on other contexts. It is unclear, for example, how we might allocate the duties of fair play amongst those who interact through complex causal pathways, such as global financial markets or as users of the Earth's atmosphere. A third articulation of fair reciprocity is more applicable to such cases because it assumes that reciprocal duties can be discharged by providing benefits for a 
'substitute' where the recipient of the debt specifies this as being preferable or where a lack of direct contact renders impossible an equivalent exchange of benefits (or costs). We might call this 'indirect reciprocity.' Perhaps the most interesting, and diffused, form of indirect reciprocity concerns the disposition to respect norms of fairness or dealings with social institutions that provide benefits to all (Arneson, 1997, p. 340).

Although justice as fair reciprocity has been criticised for neglecting the ethical importance of 'non-strategic' features of persons such as their humanity or vulnerability (Goodin, 1985, pp. 177ff; Buchanan, 1990, pp. 231ff; Barry 1995, pp. 33ff), notions of contributiveness and fair reciprocity describe an important aspect of distributive justice. As White observes, there is a 'strong contribution ethic', modelled on fairness rather than self-interest, evident in the liberal egalitarian tradition that currently dominates Anglo-American political philosophy (White, 2003, pp. 5ff). The notion of reciprocity is, for example, a central component in the literature on Unconditional Basic Income, both in terms of the problem of determining the scope of the basic income, as well as the level at which it should be set (Galston, 2001, pp. 29-33; White, 1997, pp. 318ff). It has also been invoked, often implicitly, in recent approaches to global poverty that restrict some duties to those that are members of a shared 'system of cooperation' (Pogge, 2002, pp. 198-201; Caney, 2005, pp. 102-116). Charles Beitz, for example, invokes fair reciprocity when he claims that 'the requirements of justice apply to institutions and practices (whether or not they are genuinely cooperative) in which social activity produces relative or absolute benefits or burdens that not would exist if the social activity did not take place' (Beitz, 1999, p. 131). 
The concept of fair reciprocity is, moreover, frequently invoked in discussions of climate change by policy-makers, negotiators and activists. A notable example is the exchange between the group of countries, led by the US, which is sceptical of the Kyoto Protocol to the UNFCCC, and the group of fast industrialising countries, led by India, that support the Protocol. As well as criticising the Protocol for being a threat to US economic interests, the Bush administration's position has been that the current climate architecture is unjust since it exempts developing countries from any binding emissions reductions. US involvement in any future climate architecture, by contrast, has been made conditional on the ‘meaningful participation’ of developing countries such as India and China.

The principle of 'meaningful participation' was outlined by George W. Bush at the EU summit in Gothenburg in June 2001 and continues to play a crucial part in the Bush administration's alternative to Kyoto. This focuses on voluntary mechanisms that provide incentives to help lower the 'carbon efficiency' of participating states as defined by the ratio of carbon dioxide $\left(\mathrm{CO}_{2}\right)$ emissions to overall economic activity. At the launch of this initiative in 2002, Bush called for immediate action on the part of developing countries stating that it is irresponsible to absolve them from shouldering some of the shared obligations. ${ }^{4}$ For their part, India and other developing countries have accused the US of reneging on a duty of fairness to contribute to the costs of climate change in the light of being a huge beneficiary of the practices that brought it about. They also emphasize the unfairness of setting countries reductions targets when their emissions amount to a fraction of those of the developed countries in per capita terms, and when such reductions could not be afforded without great sacrifice. ${ }^{5}$ 
While the Bush administration's approach to Kyoto is viewed by many as itself a scandalous violation of fair reciprocity (Singer, 2002, pp. 38ff; Athanasiou and Baer, 2002, pp. 115ff), it seems clear that an effective, global climate agreement will not emerge until the issue of fairness in the distribution of the costs of climate change mitigation and adaptation is resolved. Notions of fair reciprocity may be dismissed by many philosophers as outmoded, but all the indications are that they will play a vital role in this debate.

\section{CLIMATE CHANGE AND THE NON-RECIPROCITY PROBLEM}

There is now compelling evidence that the accumulation of greenhouse gases in the atmosphere since the beginning of the industrial revolution is starting to have a range of impacts on the quality of human life, and will continue to do so for many centuries. Evidence collected by the Intergovernmental Panel on Climate Change (IPCC) shows that there is no longer any reasonable doubt that the $0.6^{\circ} \mathrm{C}$ global warming witnessed in the last 100 years was caused by anthropogenic greenhouse emissions (Houghton et al., 2001, pp. 10ff). Nor is there any reason to believe that the composition of the atmosphere will stop changing in ways that affect human life as greenhouse gases continue their projected rise over the next century (Schneider and Sarukhan, 2001, pp. 77ff).

As is well known, the IPCC's assessments have informed international negotiations on adopting a coherent and binding regime of climate change in terms of mitigation (the prevention of avoidable climate change) and adaptation (the modifying of human practices to accommodate unavoidable climate change). The most prominent output of these negotiations has been the Kyoto Protocol, 
which came into force on 16 February 2005, and which requires developed countries to reduce their collective greenhouse emissions by an average of $5.2 \%$ from their 1990 levels by the end of 2012. Enthusiasts of the Protocol claim that it will save significant numbers of future persons from adverse environmental impacts while only imposing modest sacrifices on their predecessors (Singer, 2002, pp. 22ff; Athanasiou and Baer, 2002, pp. 98ff). They also maintain that problems pertaining to compliance with the terms of the Protocol, as well as the refusal of the US to ratify it, should be viewed within the context of Kyoto being a 'prototype regime' that will be replaced at a later date by a more comprehensive global agreement (DeSombre, 2004, pp. 41-46). In fact, there now exists over 40 proposed climate architectures that build on the basic elements of Kyoto in order to manage climate change beyond 2012 (Bodansky, 2004, pp. 19-58).

Sceptics of Kyoto, by contrast, hold that the Protocol is hopelessly flawed. They claim, for example, that the science that underlies the Protocol paints an overly pessimistic picture of climate change and its likely impact on human well-being (Lomborg, 2001, pp. 258ff); that the Protocol will do little to prevent dangerous climate change in its present form (Gardiner, 2004, pp. 23-39; Nordhaus, 2001); and that the socio-economic costs of Kyoto will far outweigh its modest benefits in terms of human well-being in the longer-term (Lomborg, 2001, pp. 302ff; Cline, 2004, pp. 23ff).

Recent research into long-term climate change suggests that the sceptics underestimate the likely costs of unmitigated climate change. Several IPCC authors, for example, have warned that a range of catastrophic impacts will occur if atmospheric concentrations of $\mathrm{CO}_{2}$ exceed 500 parts per million later this 
century, as is certain to be the case if global emissions remain at their present levels (Paavola and Adger, 2006; Schneider and Lane, 2006). ${ }^{6}$ The Stern Review on the Economics of Climate Change added that, if unchecked, rising greenhouse gas concentrations could lead to a reduction in global per-capita consumption of between 5 and 20 per cent by the end of the next century (Stern, 2007, Chapter 6). Yet, the empirical claims of the sceptics are not the only source of doubt about the coherence of the UNFCCC's objective to avoid 'dangerous climate change' in the name of justice. A more intrinsically ethical problem is that combating climate change for the sake of future generations will involve huge unrequitable sacrifices on the part of the present generation, and in particular the present poor, in a way that seems irreconcilable with any version of justice as reciprocity.

Suppose the Protocol, and any successor agreement, achieves the full compliance of ratifying Parties over the next 200 years. The vast majority of future individuals that will benefit from the modest amount of climate change avoided will never be in a position to repay the present generation for their sacrifice, either individually or collectively, since virtually all existing persons will be long dead before the real benefits of Kyoto and successor regimes have materialised. Reciprocity-based justice requires, by contrast, that persons provide benefits for others, including members of different nations or generations, only if the recipients are in a position to reciprocate. Persons belonging to later generations, however, can do little either to enhance or diminish the well-being of members of earlier generations. ${ }^{7}$ It would not seem just, on grounds of prudence or fairness, for earlier generations to sacrifice their well-being for the sake of their successors 
who they will never meet and who cannot contribute to their well-being. We might call this the 'non-reciprocity problem.'

The non-reciprocity problem reflects the fact that dealings between noncontemporaries are characterised by a peculiarly intractable co-ordination problem. Here, reciprocal behaviour cannot apparently emerge in order to solve 'global commons' problems that turn on the equitable distribution of rights to, and usage of, global public goods such as a hospitable climate system. Unlike contemporaneous members of different countries, the parties cannot interact and cooperate for conceptual, rather than contingent, reasons (Barry, 1989, p. 189; Gardiner, 2004, pp. 29ff). Members of earlier generations seem, in this sense, to be in a similar situation to those living in an upstream community who have realised that their industrial and agricultural practices are polluting the environment of communities living downstream at no cost to themselves. If reciprocity determines the scope and content of justice, future persons have no claims against their ancestors.

The non-reciprocity problem arises for those who are tempted to hold the following four beliefs:

(1) the performance of acts, or adoption of social policies, which threaten the well-being of members of future generations violates certain requirements of justice.

(2) requirements of justice are owed only to those who can reciprocate with those who are bound by those requirements. 
(3) reciprocity exists only between persons who can interact with each other through some direct causal pathway.

(4) it is not possible to affect the interests of those who belong to past generations.

It seems that proponents of justice as reciprocity have three options when tempted by these incompatible beliefs. First, they could abandon the thought that justice can be extended in time beyond the nearest of generations (belief 1). Second, they could abandon their commitment to some aspect of justice as reciprocity (beliefs 2 and 3). Third, they could abandon the view that persons are invulnerable to the actions of their distant successors (belief 4). The problem is that beliefs (2) and (3) seem indispensable for reciprocity theorists; belief (1) has widespread intuitive support; and belief (4) seems unavoidable on any plausible account of human well-being. It seems that, if the notion of intergenerational justice is to be defended, justice as reciprocity must be abandoned; or if justice as reciprocity is to be defended then clear norms of intergenerational justice must be abandoned.

\section{SOLVING THE NON-RECIPROCITY PROBLEM: INTERGENERATIONAL STEWARDSHIP}

Can proponents of justice as reciprocity respond to the non-reciprocity problem in a way that will contribute to the growing consensus that environmental problems that threaten the well-being of our descendants are unjust? Although the nonreciprocity problem adeptly exploits the counter-intuitive restrictiveness of self interested reciprocity, there are a number of ways in which proponents of justice as fair reciprocity might finesse the problem. For reasons of space, I concentrate 
here on the possibility of revising belief (3) in order to retain beliefs (1), (2), and (4) by developing the notion of indirect reciprocity. To recap, indirect reciprocity holds when a person or institution, $A$, discharges a duty to another person or institution, $C$, by benefiting a third person or institution, $B$, according to what can reasonably be expected to be $C$ 's bidding. In more concrete terms, the approach to the non-reciprocity problem I propose is that we modify the mechanism of interaction at the heart of justice as fair reciprocity so that (3) becomes:

(3A) reciprocity exists only between those persons who can interact with each other through some direct or indirect causal pathway.

Perhaps the most promising account of intergenerational justice that appeals to (3A) is founded on the notion of 'intergenerational stewardship.' The idea is that existing persons are bound by duties of indirect reciprocity to protect environmental and human resources for posterity in return for the benefits inherited from their ancestors. Each generation does not possess unlimited rights over the natural and human environment, but is free to make use of the world's resources so long as it does not degrade or destroy the inheritance of later generations. This does not, however, prevent a generation working to improve the quality of the resource base bequeathed to their successors by saving or through scientific and cultural achievements, or exempt those generations who have not received a fair inheritance from certain duties of conservation.

Intergenerational stewardship can be usefully contrasted with the 'communitarian' defence of intergenerational justice. Here, members of political communities have a general duty to preserve the material and non-material conditions necessary for 
the survival and flourishing of their community, which is viewed as an essential component of their sense of self (De Shalit, 1995, pp. 13-65; Marshall, 1993, pp. 105ff). Although communitarianism and stewardship have occasionally been combined in the literature, notably in the writings of Edmund Burke (Burke, 1968, pp. 120ff), they are in many ways incompatible approaches. One contrast is that communitarianism is usually presented in future-orientated terms in the sense that it recognises no obligation to reciprocate, or continue, the efforts of prior generations. Rather, as de Shalit has put it, 'our obligations to future generations derive from the sense of a community that stretches and extends over generations and into the future' (De Shalit, 1995 p. 14). Here, it is the survival of the community that matters, and this turns in most cases not on the preservation of goods inherited from our ancestors, but on the values that present and future people could be imagined to share.

Another contrast relates to substantive differences in how the views approach environmental problems. Since the stewardship model specifies the bearers and holders of duties of justice in terms of the language of reciprocal benefit, rather than of communal identity, it is potentially more inclusive than communitarian rivals as co-operative interaction regularly takes place across national borders. The result is that notions of stewardship are better placed to address 'transboundary’ problems, such as global climate change, which involve the ethical claims of non-compatriots as well as non-contemporaries. Communitarianism, by contrast, could justify a myopic response to climate change since members of the key polluting countries do not belong to the same communities, or share the same climate vulnerabilities as members of developing countries. According to the 
stewardship approach, by contrast, present persons and institutions must, to the extent that they are able, pass on the benefit of a hospitable climate system to future persons wherever they live and whatever values they hold.

While key elements of intergenerational stewardship have been defended by a number of distinguished political theorists, ${ }^{8}$ the clearest exposition of it as a development of fair reciprocity has been proposed by Lawrence Becker (Becker, 1986, pp. 229-51). Becker’s argument runs as follows. A large proportion of the benefits that people receive in their lives is produced by persons with whom they have no face-to-face, or direct, exchanges. In such cases, the identities of the producers of these benefits might be known, yet it might be impossible for the recipients to return these benefits as (i) nothing can be produced which the original producers might value or (ii) nothing could be made which could subsequently be transferred to their possession. This does not mean, however, that there is no obligation to reciprocate for such benefits since an obligation of reciprocity may remain in place even in situations where a mutual exchange of benefits is impossible. To determine whether one has a duty to reciprocate, one must ask whether one has been in receipt of a good 'for which some sort of fitting and proportional return is possible, and it is often perfectly fitting to make our returns to people other than those who have benefited us' (Becker, 1986, pp. 230231; Becker, 2005, pp.24ff). Since our ancestors were responsible for creating many of the benefits that we currently enjoy, Becker adds that duties of fair reciprocity are also owed in a range of circumstances to those no longer alive; and a subset of such duties can only be discharged by producing appropriate benefits for the sake of members of future generations. 
There are four main steps in Becker's defence of duties of intergenerational stewardship (while Becker focuses on duties to reciprocate for the benefits conferred by past institutions, I assume that the account can be extended to cover the duties owed to past individuals from whom we have benefited).

(1) many of the benefits enjoyed by present persons were produced by past persons with the intention that they be preserved indefinitely or for a specified amount of time.

(2) although the intended recipients of these benefits are not always specified, these benefits are nonetheless intended for someone.

(3) the obligation to pass on these benefits to future persons is analogous to the obligation to reciprocate for benefits received from unknown contemporaries.

(4) it is 'fitting and proportionate' that existing persons pass on these benefits to our successors in order to 'satisfy the moral requirements of reciprocity’ (Becker, 1986, p. 231).

So the 'fitting and proportionate return' in Becker's argument is owed to past persons, the obligation binds present persons, and the performance associated with this obligation is directed towards future persons.

The stewardship approach, as presented by Becker, offers some important insights about relations between generations. Because it fuses elements of benefit, cost and indirect reciprocity, the approach does not require later generations to pass on goods they have inherited if they could only satisfy their basic needs by consuming them. The cost of providing an equivalent benefit in such cases would 
be prohibitive and would violate the ideal of 'balanced exchange' according to which equivalent exchanges of benefits are desirable but must also be weighed against other considerations, such as differential capabilities. Becker stops short of endorsing cost reciprocity, however, since the effort required to produce a given benefit is given no independent value of its own. The upshot is that the benefits to be secured for future generations are determined primarily by the actual bundle of goods inherited, rather than the overall capacity of each generation to provide benefits for the sake of their successors.

The weaknesses of Becker's argument are revealed by an analysis of premises (1) and (4) of the argument. Suppose we grant that certain duties can be discharged only if we perform actions that benefit someone other than the owed party, as well as the claim that some duties are owed to past persons and can only be discharged by benefiting future persons. Premise (1) is vulnerable since the vast majority of benefits passed down through the generations were not explicitly bequeathed on the understanding that they be preserved for the sake of remote future generations. Premise (4), by contrast, assumes precisely that it is fitting and proportionate that such goods be saved, rather than consumed, by present persons even though we had no choice but to accept them, and this might seem hard to believe.

The claim that benefits arising as unintended side-effects of other actions give rise to duties of fair requital on the part of their recipients is highly controversial. Suppose, for example, that a government adopts an initiative to reduce $\mathrm{CO}_{2}$ emissions solely for the benefits this will have for the well-being of existing citizens. A century later it is demonstrated that this prior initiative also led to a reduction, for reasons that are poorly understood, in the incidence of certain 
varieties of cancer. We would not usually suppose that those belonging to later generations owe any debt of gratitude to their predecessors for this unintentionally produced benefit. It just seems a matter of good fortune. Becker, however, argues that the receipt of unintentionally produced goods gives rise to a range of duties of reciprocity on the part of those that receive them, in particular to sustain and preserve the institutions or practices which enabled their production. 'We owe to the future', he argues, 'only as much as we were given, and we must make our 'returns' in the very way we were benefited (e.g. intentionally or unintentionally), and to the very institutions that benefited us’ (Becker, 1986, pp. 238-9).

Aside from the conceptual problems associated with this imaginative broadening of fair reciprocity, there also arise some potentially disturbing consequences that must be evaluated. For, if we accepted that unintentionally produced benefits gave rise to the same range of duties as intentionally produced benefits, it would seem that we would be in danger of being swamped by duties of reciprocation. Should the present inhabitants of the UK feel obliged to the Romans, for example, for their unwitting role in the development of the country's present road network? How might such an obligation be discharged? Are the present inhabitants of developed countries in debt to their ancestors for goods and services (such as cheap air travel and the internet) which would not have been invented had it not been for the industrial revolution?

I say no more about the problem of unintentionally produced benefits because it seems clear that at least some of the benefits created for present persons were intentionally produced. Indeed, since the late 1980s, individuals, nongovernmental organisations and governments have fought hard for global 
agreements on greenhouse gas reductions for the sake of future generations, so it is clear that acts and policies designed to protect the well-being of our successors need not be unplanned. Turning to the issue of 'involuntary receipt', the conceptual difficulties for Becker's stewardship approach are less tractable. The key question, here, is the following: do those who benefit from the co-operative activities of others owe duties of fairness to those that produced the benefits in question?

In an influential discussion of fairness and political obligation which has clear relevance for broader discussions of distributive justice, John Rawls argued that there were two key conditions for an affirmative answer: (i) that the benefit providing institution is just and (ii) that the benefits concerned are voluntarily accepted. ${ }^{9}$ Let us put Rawls' first condition to one side on the grounds that it introduces unnecessary complications. If fair reciprocity concerns the making of fitting and proportionate returns for benefits that one receives from participating in voluntary social activities, the fact that one did not willingly co-operate in the production of certain goods would have two implications. First, one is bound by no duty to contribute to the production costs of the benefits received; second, one has no right to the benefits in the first place.

While the voluntarist conception of fairness has some intuitive appeal, some theorists have suggested that benefits that have not been accepted voluntarily can give rise to obligations of requital in special circumstances (Arneson, 1982, pp. 632ff; Becker, 1986, pp.361ff; Klosko, 1987, pp. 353ff). These circumstances may extend to the provision of excludable goods, such as income or property, but arise in particular when the benefits concerned are connected with the 
preservation of goods that cannot be enjoyed by some without being enjoyed by all. The idea is that at least some of these public goods generate duties of fair reciprocity on their beneficiaries to contribute to the costs of their production even though they cannot be received voluntarily.

The public goods that most plausibly force a suspension of the voluntary receipt condition are those that can be viewed as indispensable for a life of decent quality, such as national defence, law and order, or a habitable biosphere. Such goods, as Klosko has put it, are 'presumptively beneficial' in the sense that they provide benefits which 'all members of the community want, whatever else they want, regardless of what their rational plans are in detail' (Klosko, 1992, p. 39). It is this element of indispensability that obligates everyone to cooperate in providing presumptively beneficial public goods, for it can be assumed that any reasonable person 'would pursue them (and bear their associated costs) if this were necessary for their receipt' (Klosko, 1992, p. 43).

The indispensable benefit provided by an atmosphere that is hospitable to human life constitutes a particularly apt example for defenders of non-voluntarist approaches to fair reciprocity and intergenerational justice. Although concentrations of greenhouse gases have been rising as a result of human activity since 1760, members of the present generation have been bequeathed an atmospheric system largely devoid of dangerous impacts. Few scientists believe that the atmospheric concentrations of $\mathrm{CO}_{2}$ witnessed before 1980, if stabilised, would bring about dangerous climate change despite the wide range of figures offered for the threshold at which concentrations of $\mathrm{CO}_{2}$ become 'dangerous' for human life. This suggests that present members of developed countries not only 
have reason to value the benefits provided by a hospitable climate system, but also that the benefits they currently derive from an environment devoid of dangerous climate change far outweigh the sacrifices they are currently being asked to make to support the current global climate regime.

Of course, if too little is done to mitigate climate change over the next century, remote future generations may find themselves in a position where they are unencumbered by duties of intergenerational reciprocity. This is because there can be no duty of fair reciprocity to pass on what one has not received. Yet, the task at hand must be to define and explain the duties that existing individuals and institutions have to protect the atmosphere for the sake of contemporaries and non-contemporaries. In this sense, there is much that the existing generation can do (and ought to do) as a matter of fair reciprocity to avoid dangerous climate change. Measures of mitigation could be adopted to increase energy efficiency in both the industrial and domestic sectors; transport practices could be altered; and more efficient land management practices could be adopted (Markandya and Halsnaes, 2001, pp. 474ff).

Meanwhile, a range of adaptation measures could also be implemented that would modify human practices to accommodate climate changes that are no longer avoidable. Water security could be enhanced in many areas by improved flood defences; human health impacts could be minimized by improved public health infrastructure in communities vulnerable to extreme weather events; and the socio-economic infrastructure of vulnerable countries and regions could be protected by improved planning and the strategic relocation of industrial buildings away form coastal areas (McCarthy et al., 2001, pp. 9ff). In each case, the 
motivating idea is that the present generation is bound by duties of fair reciprocity to ensure that our successors may also enjoy the benefit of a climate system that is hospitable for human life.

\section{CONCLUSION}

Although the stewardship approach to intergenerational justice requires further exploration and clarification, it is a clear addition to the family of ethical approaches that converge on requiring the preservation of environmental goods for the sake of future generations. Even if recognising duties of stewardship does not support any particular climate policy, it does further undermine the restrictive ethics that lie behind some climate sceptic positions. According to this restrictive ethics, the interests of future persons have no place in discussions of distributive and environmental justice because the unborn have no claims of justice, or the few claims they do have should be heavily discounted relative to those of existing persons (Schwartz, 1978; Beckerman and Pasek, 2001, pp. 11ff). The message of such 'generocentrist' arguments is that our concerns for posterity are best explored in terms of charity rather than entitlement (Heyd, 1992, pp. 80ff). Considerations of intergenerational stewardship, however, undermine this line of reasoning: each generation is required by justice to protect the climate system for their successors.

Can we go beyond this cautious conclusion and posit any direct link between intergenerational stewardship and climate change policy? I would suggest that duties of stewardship strengthen the case for deep cuts in greenhouse emissions, 
as well as financial transfers to aid climate adaptation, that go well beyond those included in the Kyoto Protocol. This is because stewardship provides the philosophical basis for a strict egalitarian conception of sustainable development according to which each generation is required 'to conserve the diversity and quality of natural and cultural resources for present and future generations and to ensure equitable access to the use of these resources' (Brown Weiss, 1992, p. 47; Arrow et al., 1996, p. 140). It is notable that proponents of climate policies that appeal to egalitarian conceptions of sustainability, such as the increasingly popular 'Contraction and Convergence'10 proposal, have generally avoided the language of reciprocity. Other ethical principles, often concerned with the harms we inflict on the interests of future persons through our negligent environmental behaviour, have been pre-eminent. Yet, the duties of conservation defined by intergenerational stewardship fit well with climate policies that extend a principle of equal usage of the climate system to members of different nations and generations, and condemn as unjust policies, such as the 'carbon intensity' approach outlined earlier, that deny this principle.

\section{References}

Adger, W. N., Paavola, J., Huq, S. and Mace, M.J. (2006) 'Towards Justice in Adaptation to Climate Change', in N. Adger et al. (eds) Fairness in Adaptation to Climate Change. Boston, MA: MIT Press, pp. 1-19.

Arneson, R. (1982) 'The Principle of Fairness and Free-Rider Problems', Ethics, 92, pp. 616-633.

Arneson, R. (1997) 'Egalitarianism and the Undeserving Poor', The Journal of Political Philosophy 5(4), pp. 327-350.

Arrow, K.J., Cline, R., Maler, K-G. Munasinghe, M., Squitieri, R. and Stigliz, J.E. (1996) 'Intertemporal Equity, Discounting, and Economic Efficiency', in J. Bruce et al (eds) 
Climate change 1995: Economic and Social Dimensions of Climate Change. Cambridge: Cambridge University Press, pp. 125-144.

Athanasiou, T. and Baer, P. (2002) Dead Heat: Global Justice and Global Warming. New York: Seven Stories Press.

Baier, A. (1981) 'The Rights of Past and Future Persons', in E. Partridge, Responsibilities to Future Generations. Buffalo: Prometheus Books, pp. 171-183.

Ball, T. (2001) 'New Ethics for Old? Or, How (Not) to Think About Future Generations', Environmental Politics, 10, Spring, pp. 89-110.

Banuri, T., Göran-Mäler, K., Grubb, M. Jacobson, H.K. and Yamin, F. (1996) 'Equity and Social Considerations', in James Bruce et al (eds) Climate change 1995: Economic and Social Dimensions of Climate Change. Cambridge: Cambridge University Press, pp. 79-124.

Banuri, T. and Weyant, J. (2001) 'Setting the Stage: Climate Change and Sustainable Development', in B. Metz, O. Davidson, R. Swart and J. Pan (eds) (2001) Climate Change 2001: Mitigation. Cambridge: Cambridge University Press, pp. 73-114.

Barry, B. (1989) Theories of Justice. Hemel Hempstead: Havester-Wheatsheaf.

Barry, B. (1995) Justice as Impartiality. Oxford: Oxford University Press.

Becker, L. C. (1986) Reciprocity. London: Routledge.

Becker, L. C. (2005) 'Reciprocity, Justice, and Disability', Ethics, 116, October, pp.3-39.

Beckerman, W. and Pasek, J. (2001) Justice, Posterity and the Environment. Oxford: Oxford University Press.

Beitz, C. (1999) Political Theory and International Relations. Princeton, NJ: Princeton University Press.

Bodansky, D. (2004) International Climate Efforts Beyond 2012: A Survey of Approaches. Washington, DC: Pew Center on Global Climate Change.

Broome, J. (1992) Counting the Cost of Global Warming. Cambridge: White Horse Press.

Brown Weiss, E. (1992) In Fairness to Future Generations: International Law, Common Patrimony. Tokyo: United Nations University.

Buchanan, A. (1990) 'Justice as Reciprocity Versus Subject-Centred Justice’, Philosophy and Public Affairs, 19(3), Summer, 227-252.

Burke, E. (1968) Reflections on the Revolution in France. London: Penguin.

Caney, S. (2005) Justice Beyond Borders: A Global Political Theory. Oxford: Oxford University Press.

Cline, W. (2004) 'Climate Change’, in B. Lomborg (ed), Global Crises, Global Solutions. Cambridge: Cambridge University Press, pp. 13-43.

Cullity, G. (1995) 'Moral Free-riding', Philosophy and Public Affairs, 24, 3-34.

De Shalit, A. (1995) Why Posterity Matters. London: Routledge.

DeSombre, E.R. (2004) 'Global Warming: More Common Than Tragic', Ethics and International Affairs, 18(1), 41-46. 
Galston, W. G. (2001) 'What about reciprocity?', in J. Cohen and J. Rogers (eds) What's Wrong with a Free Lunch? Boston: Beacon Press, pp.29-33

Gardiner, S.M. (2004) 'The Global Warming Tragedy and the Dangerous Illusion of the Kyoto Protocol'?', Ethics and International Affairs, 18(1), 23-39

Gauthier, D. (1986) Morals by Agreement. Oxford: Clarendon.

Goodin, R. (1985) Protecting the Vulnerable. Chicago: University of Chicago Press.

Hart, H.L.A. (1955), ‘Are There Any Natural Rights’, Philosophical Review 64, pp.17591.

Heyd, D. (1992) Genethics. Berkeley: University of Caifornia Press.

Houghton, J.T., Ding, Y., Griggs, D.J., Noguer, M., van der Linden, P.J., Dai, X., Maskell, K., and Johnson, C.A. (eds) (2001) Climate Change 2001: The Scientific Basis. Cambridge: Cambridge University Press.

Jamieson, D. (2003) 'Ethics, Public Policy, Global Warming', in Morality's Progress: Essays on Humans, Other Animals, and the Rest of Nature. Oxford: Clarendon Press, pp. 282-295.

Keeling, C.D. and Whorf, T.P. (2005) 'Atmospheric $\mathrm{CO}_{2}$ records from sites in the SIO air sampling network', in US Carbon Dioxide Information Analysis Center, Trends: A Compendium of Data on Global Change (Oak Ridge, TN: US Department of Energy).

Klosko, G. (1987), 'The Principle of Fairness and Political Obligation', Ethics 97, January, pp. 353-362.

Klosko, G. (1992) The Principle of Fairness and Political Obligation. Oxford: Rowman and Littlefield.

Kumar, R. (2003) 'Who Can Be wronged?’, Philosophy and Public Affairs, 31(2), 99118.

Laslett, P. (1992) 'Is There a Generational Contract?' in P. Laslett and J.S. Fishkin (eds) Justice Between Age Groups and Generations. New Haven: Yale University Press, pp. 24-47.

Lomborg, B. (2001) The Skeptical Environmentalist: Measuring the Real State of the World. Cambridge: Cambridge University Press.

Markandya, A. and Halsnaes, K. (2001), 'Costing Methodologies', in B. Metz et al., Climate Change 2001: Mitigation. Cambridge: Cambridge University Press, pp. 451495.

Marshall, P. (1993) 'Thinking for Tomorrow', Journal of Applied Philosophy, 10(1), 105-13.

McCarthy, J.J., Canziani, O.F., Leary, N.A., Dokken, D.J. and White, K. S. (eds) (2001) Climate Change 2001: Impacts, Adaptation, and Vulnerability. Cambridge: Cambridge University Press.

McMichael, A.J. and Githeko, A. (2001) 'Human Health', in J.J. McCarthy et al. (eds) (2001) Climate Change 2001: Impacts, Adaptation, and Vulnerability. Cambridge: Cambridge University Press, pp. 451-485.

Nozick, R. (1974) Anarchy, State and Utopia. New York: Basic Books.

Nordhaus, W.D. (2001), ‘Global Warming Economics’, Science, 294, 9 November, 12831284. 
Oreskes, N. (2004) ‘The Scientific Consensus on Climate Change’, Science 306, 1686.

O’Neill, J. (1995) Ecology, Politics and Policy. London: Routledge.

Page, E. (2006) Climate Change, Justice, and Future Generations. Cheltenham: Edward Elgar.

Paavola, J. and Adger, N.J. (2006) 'Fair Adaptation to Climate Change', Ecological Economics, in press.

Pogge, T. (2002) World Poverty and Human Rights. Cambridge: Polity.

Rawls, J. (1971) A Theory of Justice. Cambridge, MA: Harvard University Press.

Schellnhuber, H.J., Gramer, W., Nakicenovic, N., Wigley, T. and Yohe, G. (eds) (2006) Avoiding Dangerous Climate Change. Cambridge: Cambridge University Press.

Schneider, S. and Sarukhan, J. (2001), 'Overview of Impacts, Adaptation, and Vulnerability to Climate Change', in J.J. McCarthy et al., Climate Change 2001: Impacts, Adaptation, and Vulnerability. Cambridge: Cambridge University Press, pp. 75-103.

Schneider, S. and Lane, J. (2006) 'An Overview of 'Dangerous Climate Change', in H.J. Schellnhuber et al. (eds) Avoiding Dangerous Climate Change. Cambridge: Cambridge University Press, pp. 7-27.

Schwartz, T. (1978) 'Obligations to Posterity', in R.I. Sikora and B.M. Barry (eds) Obligations to Future Generations (Philadelphia: Temple University Press), pp. 3-13.

Shue, H. (2003) 'Climate', in D. Jamieson (ed) A Companion to Environmental Philosophy. Oxford: Blackwell, pp. 449-59.

Singer, P. (2002) One World. London: Yale University Press.

Simmons, A. J. (1979) Moral Principles and Political Obligations. Princeton, NJ: Princeton University Press.

Smith, S.R. (2001) 'The Social Construction of Talent: A Defence of Justice as Reciprocity', Journal of Political Philosophy 9(1), March, 19-37.

Smith, S.R. (2003) Defending Justice as Reciprocity: An Essay on Social Policy and Political Philosophy. Lampeter: Edwin Mellen.

Stern, N. (2007) Stern Review on the Economics of Climate Change. Cambridge: Cambridge University Press.

Tol, R.S.J. (2002) 'Estimates of the Damage Costs of Climate Change', Environmental and Resource Economics 21, 47-73.

United Nations (1995) United Nations Framework Convention on Climate Change. London: HMSO Books.

White, S. (1997) 'Liberal equality, exploitation, and the case for an unconditional basic income', Political Studies, 45(2), 312-326.

White, S. (2003) The Civic Minimum: On the Rights and Obligations of Economic Citizenship. Oxford: Oxford University Press.

\section{NOTES}

I am grateful to Simon Caney, Clare Heywood, Ludvig Beckman, Jouni Reinkainen, and three anonymous reviewers for their excellent comments on an earlier draft of this paper. 
I would also like to acknowledge the support of the UK Arts and Humanities Research Council, which funds my post at Birmingham as part of the 'Global Justice and the Environment' research project.

${ }^{1}$ A widely cited article by Naomi Oreskes reports that, of 928 articles published in peer reviewed scientific journals between 1993 and 2003 with abstracts containing the phrase 'global climate change', none disputed the consensus position that the Earth's climate has changed, and will continue to change, as a result of the anthropogenic greenhouse effect (Oreskes, 2004, p. 1686).

${ }^{2}$ Banuri et al., 1996, pp. 83ff; Arrow et al., 1996; Banuri and Weyant, 2001; Athanasiou and Baer, 2002, pp. 98ff; Jamieson, 2003, pp. 283ff; Shue, 2003.

${ }^{3}$ In the text, a person's 'well-being' or 'quality of life' refers to how well that person's life is going, for that person. Several theories of well-being are defended in the literature, the three most prominent focusing on the presence of pleasurable conscious states (hedonism), the fulfilment of desires (desire fulfilment theory), and the possession of goods that are of objective value (objective list theory). However, the discussion avoids endorsing any given theory of well-being, or the view, known as 'welfarism', that human well-being is the only thing of ultimate moral importance.

${ }^{4}$ Speech to the National Oceanic and Atmospheric Administration, Silver Spring, Maryland, 14 February 2002.

${ }^{5}$ Former Indian Prime Minister Atal Behari Vajpayee, for example, articulated this position forcefully at the 2002 UN climate change conference in Delhi. See BBC Online, 'India rejects climate change pressure', Wednesday 30 October 2002 (http://news.bbc.co.uk/1/hi/world/south_asia/2374551.stm).

${ }^{6}$ Observations from the Mauna Loa Observatory in Hawaii show that atmospheric $\mathrm{CO}_{2}$ concentrations reached 377 parts per million in 2004 and are currently growing at a rate of more than 2 parts per million per year. This figure compares with that of 316 parts per million in 1959 and 280 part per million in 1760, the date commonly used to mark the beginning of the industrial revolution (Keeling and Whorf, 2005). The Stern Review on the Economics of Climate Change note that even this figure gives a misleadingly low figure for overall greenhouse gas concentrations for it excludes the climate forcing role of Methane. Stern suggests that the current (2006) atmospheric concentration of the six major greenhouse gases combined (quoted in terms of the equivalent concentration in $\mathrm{CO}_{2}$ ) is roughly 430 parts per million (Stern, 2007, Chapter 1).

${ }^{7}$ Some have suggested that, while people do much cannot generally further or diminish the well-being of the dead, a certain degree of intergenerational reciprocity flows from the ability of later generations to further the posthumous reputations of their ancestors and/or fulfil the future-orientated projects that their ancestors commenced (see, for example, O’Neill, 1995, pp. 28ff). While this is without doubt an innovative approach to human well-being, appeals to posthumous benefit seem of limited application to the issues discussed in the text as both the quantity and quality of the intergenerational reciprocity created by such appeals is quite limited.

${ }^{8}$ Baier, 1981; Laslett, 1992; Brown Weiss, 1992, pp. 47ff; Ball, 2001, pp. $93 f f$.

${ }^{9}$ Rawls, 1971, pp. 111ff. See also Hart, 1955, p.185; Nozick, 1974, p. 95; Simmons, 1979, pp.103ff; Cullity, 1995, pp. 9ff.

${ }^{10}$ The contraction and convergence climate architecture has three main elements. First, each person on the planet is granted an equal right to emit carbon by virtue of their equal right to use the benefits provided by the atmospheric commons. Second, a 'global ceiling' for greenhouse gas emissions is set based on the amount the global environment can withstand without dangerous climate change taking place. Third, each country is allocated a yearly 'carbon emissions budget' consistent with the global ceiling not being exceeded. The name of the approach comes from the notion that, over time, it aims to bring about a 
stabilisation, and later a contraction, in global greenhouse emissions so that they stay below a safe level; and that, in the longer term, all countries will converge on a roughly equal level of per-capita emissions (Meyer, 2000, pp. 56ff). 